\title{
Errata to "Coronal Alignment of the Lower Limb and the Incidence of Constitutional Varus Knee in Korean Females"
}

Moo-Ho Song, $\mathrm{MD}^{1}$, Seong-Ho Yoo, $\mathrm{MD}^{1}$, Suk-Woong Kang, $\mathrm{MD}^{1}$, Yeong-Joon Kim, $\mathrm{MD}^{1}$, Gyu-Taek Park, $\mathrm{MD}^{1}$, and Yong-Seon Pyeun, $\mathrm{MD}^{2}$

Departments of ${ }^{1}$ Orthopaedic Surgery and ${ }^{2}$ Radiology, Daedong General Hospital, Busan, Korea

http://dx.doi.org/10.5792/ksrr.2015.27.1.49

Knee Surg Relat Res 2015;27(1):49-55

Errata are published when significant errors related to patient care, scientific data or record-keeping, or authorship are discovered after printing. Errata also appear in PDF files downloaded from jksrr.org.

On page 51, Fig. 4 should be replaced with the following figure.

On page 52, Table 4 should be replaced with the following table.

On page 53, line 37, Bellemann et al. ${ }^{6}$ should be corrected to Bellemans et al. ${ }^{6}$.

Table 4. Distribution of Hip-Knee-Ankle Angle (HKAA)

\begin{tabular}{lccc}
\hline \multicolumn{1}{c}{ Variable } & $\begin{array}{c}\text { Right HKAA } \\
(\mathrm{n}=118)\end{array}$ & $\begin{array}{c}\text { Left HKAA } \\
(\mathrm{n}=118)\end{array}$ & $\begin{array}{c}\text { Total } \\
(\mathrm{n}=236)\end{array}$ \\
\hline${\text { Less than }-3^{\circ}}^{\circ}$ & $29(24.58)$ & $19(16.10)$ & $48(20.34)$ \\
$-3^{\circ}-0^{\circ}$ & $63(53.39)$ & $64(54.24)$ & $127(53.81)$ \\
$0^{\circ}-3^{\circ}$ & $25(21.17)$ & $34(28.81)$ & $59(25.00)$ \\
${\text { More than } 3^{\circ}}^{\circ}$ & $1(0.85)$ & $1(0.85)$ & $2(0.85)$ \\
\hline
\end{tabular}

Values are presented as number (\%).

The Editorial Office apologizes for any inconvenience this may have caused.

Correspondence to: Seong-Ho Yoo, MD

Department of Orthopaedic Surgery, Daedong General Hospital, 187

Chungnyeol-daero, Dongnae-gu 607-711, Busan, Korea

Tel: +82-451-554-8996, Fax: +82-451-553-7575

E-mail: mhsong21@hanmail.net

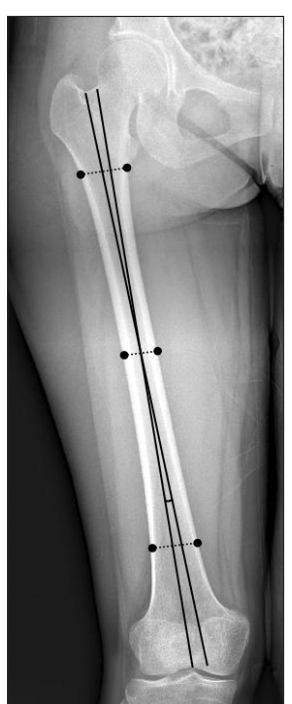

Fig. 4. Femoral bowing angle.

This is an Open Access article distributed under the terms of the Creative Commons Attribution Non-Commercial License (http://creativecommons.org/licenses/by-nc/4.0/) which permits unrestricted non-commercial use, distribution, and reproduction in any medium, provided the original work is properly cited. 